\title{
Knowledge, attitude and practice of infection prevention and control among healthcare workers: one year after an outbreak of nosocomial Lassa fever in a tertiary hospital in southeast Nigeria
}

\author{
${ }^{* 1,2}$ Adeke, A. S., ${ }^{3}$ Onoh, R. C., ${ }^{1,2}$ Umeokonkwo, C. D., ${ }^{1}$ Azuogu, B. N., and ${ }^{4}$ Ogah, E. O.
}

${ }^{1}$ Department of Community Medicine, Alex Ekwueme Federal University Teaching Hospital, Abakaliki, Ebonyi State, Nigeria

${ }^{2}$ Nigeria Field Epidemiology and Laboratory Training Program, Abuja, Nigeria

${ }^{3}$ Department of Obstetrics and Gynaecology, Alex Ekwueme Federal University Teaching Hospital, Abakaliki, Ebonyi State, Nigeria

${ }^{4}$ Department of Pediatrics, Alex Ekwueme Federal University Teaching Hospital, Abakaliki, Ebonyi State, Nigeria *Correspondence to: azukaadeke@gmail.com; +2348035285133

\begin{abstract}
:
Background: With the rise in cases of Lassa fever in recent times in West Africa, the healthcare setting continues to pose significant risk especially among healthcare workers (HCWs) for diseases like Lassa fever that are transmitted via contact with blood and other body fluids. We therefore assessed the knowledge, attitude and practice (KAP) of infection prevention and control (IPC) one year after an outbreak of nosocomial transmission of Lassa fever in the study hospital.

Methodology: A cross-sectional study of HCWs was conducted in Alex Ekwueme Federal University Teaching Hospital, Abakaliki, Ebonyi State, a tertiary hospital designated for Lassa fever treatment in southeast Nigeria. A total of $631 \mathrm{HCWs}$ selected by systematic random sampling were surveyed using self-administered questionnaire to determine the KAP of IPC. Data analysis was done with EPI INFO version 7.2 and Microsoft Excel 2016, and Chi square statistic was used to examine relationship between variables at $5 \%$ level of significance.

Results: Only $287(51.1 \%)$ of the 562 respondent HCWs had good knowledge of IPC, $442(78.6 \%)$ had good attitude towards IPC, and $268(47.7 \%)$ had good practice of IPC. Socio-demographic predictors of IPC knowledge included being a medical laboratory scientist ( $\mathrm{AOR}=0.5 ; 95 \% \mathrm{CI}=0.29-0.83 ; p=0.009)$, tertiary education level $(A O R=7.0 ; 95 \% C I=1.11-44.60 ; p=0.038)$, and work experience of $\geq 7$ years $(A O R=2.3 ; 95 \% C I=1.47-3.57$; $p<0.001)$. Male gender $(A O R=1.9 ; 95 \% C I=1.06-3.42 ; p=0.031)$, nurse professional $(A O R=6.5 ; 95 \% C I=2.67-$ $15.81 ; p<0.001)$ and work experience of $\geq 7$ years $(A O R=2.5 ; 95 \% C I=1.37-4.54 ; p=0.003)$ were predictors of good attitude towards IPC. Also, nurse professional (AOR=3.1; $95 \% \mathrm{CI}=1.79-5.20 ; p<0.001$ ) and married status $(A O R=1.6 ; 95 \% C I=1.05-2.55 ; p=0.028)$ were predictors of good practice of IPC among the respondents. Conclusions: The study demonstrated that knowledge and practice of IPC was low in the study location despite the interventions that had been instituted to improve the IPC framework. Therefore, there is need to adapt approaches that will influence behavior change towards IPC in the course of the in-service trainings being conducted in the hospital.
\end{abstract}

Keywords: Infection prevention, Lassa fever, Nosocomial, KAP, Healthcare workers

Received Apr 27, 2021; Revised Aug 7, 2021; Accepted Aug 8, 2021

Copyright 2021 AJCEM Open Access. This article is licensed and distributed under the terms of the Creative Commons Attrition 4.0 International License $<$ a rel="license" href="http://creativecommons.org/licenses/by/4.0/", which permits unrestricted use, distribution and reproduction in any medium, provided credit is given to the original author(s) and the source. Editor-in-Chief: Prof. S. S. Taiwo

\section{Connaissances, attitude et pratique de la prévention et du contrôle des infections chez les agents de santé: un an après une épidémie de fièvre de Lassa nosocomiale dans un hôpital tertiaire du sud-est du Nigeria}

\author{
*1,2Adeke, A. S., ${ }^{3}$ Onoh, R. C., ${ }^{1,2}$ Umeokonkwo, C. D., ${ }^{1}$ Azuogu, B. N., et ${ }^{4}$ Ogah, E. O.
}

${ }^{1}$ Département de médecine communautaire, Hôpital universitaire fédéral Alex Ekwueme, Abakaliki, État d'Ebonyi, Nigéria

${ }^{2}$ Programme de formation en épidémiologie de terrain et en laboratoire au Nigéria, Abuja, Nigéria

${ }^{3}$ Département d'obstétrique et de gynécologie, Hôpital universitaire fédéral Alex Ekwueme, Abakaliki, État d'Ebonyi, Nigéria 
${ }^{4}$ Département de pédiatrie, Hôpital universitaire fédéral Alex Ekwueme, Abakaliki, État d'Ebonyi, Nigéria *Correspondance à: azukaadeke@gmail.com; +2348035285133

\begin{abstract}
Abstrait:
Contexte: Avec l'augmentation récente des cas de fièvre de Lassa en Afrique de l'Ouest, le milieu de la santé continue de présenter un risque important, en particulier chez les travailleurs de la santé (TS) pour des maladies comme la fièvre de Lassa qui se transmettent par contact avec le sang et d'autres fluides corporels. Nous avons donc évalué les connaissances, l'attitude et la pratique (CAP) de la prévention et du contrôle des infections (PCI) un an après une épidémie de transmission nosocomiale de la fièvre de Lassa dans l'hôpital de l'étude.

Méthodologie: Une étude transversale des travailleurs de la santé a été menée à l'hôpital universitaire fédéral Alex Ekwueme, à Abakaliki, dans l'État d'Ebonyi, un hôpital tertiaire désigné pour le traitement de la fièvre de Lassa dans le sud-est du Nigéria. Un total de 631 TS sélectionnés par échantillonnage aléatoire systématique ont été interrogés à l'aide d'un questionnaire auto-administré pour déterminer le CAP de la CIP. L'analyse des données a été effectuée avec EPI INFO version 7.2 et Microsoft Excel 2016, et la statistique du Chi carré a été utilisée pour examiner la relation entre les variables à un niveau de signification de $5 \%$.

Résultats: Seuls $287(51,1 \%)$ des 562 TS interrogés avaient une bonne connaissance de la CIP, 442 (78,6\%) avaient une bonne attitude envers la CIP et $268(47,7 \%)$ avaient une bonne pratique de la CIP. Les prédicteurs sociodémographiques des connaissances en CIP comprenaient le fait d'être un scientifique de laboratoire médical $(A O R=0,5$; IC à $95 \%=0,29-0,83 ; p=0,009)$, le niveau d'études supérieures ( $A O R=7,0$; IC à 95\% $=1,11-44,60$; $p=0,038)$ et une expérience de travail $\geq 7$ ans (AOR=2,3; IC à $95 \%=1,47-3,57 ; p<0,001)$. Sexe masculin $(\mathrm{AOR}=1,9 ; \mathrm{IC}$ à $95 \%=1,06-3,42 ; p=0,031)$, infirmier professionnel $(\mathrm{AOR}=6,5 ;$ IC à $95 \%=2,67-15,81 ; p<0,001)$ et expérience professionnelle de $\geq 7$ ans ( $A O R=2,5$; IC à $95 \%=1,37-4,54 ; p=0,003)$ étaient des prédicteurs d'une bonne attitude envers la CIP. De plus, l'infirmière professionnelle ( $A O R=3,1$; à $95 \%$ IC $=1,79-5,20$; $p<0,001)$ et le statut de personne mariée ( $\mathrm{AOR}=1,6$; à $95 \% \mathrm{IC}=1,05-2,55 ; p=0,028)$ étaient des prédicteurs de bonne pratique de la CIP parmi les répondants.

Conclusions: L'étude a démontré que les connaissances et la pratique de la CIP étaient faibles dans le lieu de l'étude malgré les interventions qui avaient été instituées pour améliorer le cadre de la CIP. Par conséquent, il est nécessaire d'adapter les approches qui influenceront le changement de comportement envers la CIP au cours des formations en cours d'emploi menées à l'hôpital.
\end{abstract}

Mots clés: Prévention des infections, Fièvre de Lassa, Nosocomiale, CAP, Personnel de santé

\section{Introduction:}

In West Africa, Lassa fever is one of the infectious diseases with a rise in cases in recent times (1). Within the West African region, an estimated 300000-500000 cases of the disease occur with associated annual deaths of about 5000 (2). Nigeria contributed the highest burden of the disease with upsurge in the number of cases in the past few years (3). The healthcare setting poses significant risk for diseases such as Lassa fever that are transmitted via contact with blood and other body fluids. Healthcare workers (HCWs) are at high risk of transmission of infectious diseases in the course of their work (4). This may be worse in resource-constrained settings due to deficiencies in human resources for health as well as poor infection prevention and control (IPC) (5)

Ebonyi is one of the high-burdened States for Lassa fever in Nigeria. The State has been recording outbreak of Lassa fever since 2005 (6), with several events of nosocomial spread of the infection among HCWs in the State (6-8). Following the outbreak of Lassa fever in 2018, an assessment was done in the study location by the National Rapid Response Team deployed for the outbreak in the State, and the assessment revealed that there were gaps in the practice and infrastructure for IPC in the hospital (9). Recommendations were also made by the Team which included raising awareness of IPC among the HCWs and provision of necessary materials for IPC (9).
Some interventions had been instituted to improve the IPC framework in the State and the study location.

IPC is a scientific approach and practical solution designed to prevent harm caused by infection to patients and HCWs especially in hospital setting (10). It is vital to HCWs and patients at every single healthcare encounter. The aim of this study therefore is to assess the situation of infection control one year after an outbreak of nosocomial Lassa fever in the study hospital.

\section{Materials and method:}

\section{Study design and setting}

We conducted a cross-sectional study among HCWs in Alex Ekwueme Federal University Teaching Hospital designated for Lassa fever treatment in southeast Nigeria. It is a 720-bed hospital located in Abakaliki, Ebonyi State (11). The hospital has over 4,000 staff comprising core and non-core HCWs. Doctors, nurses, medical laboratory scientists and the cleaning staff were recruited for the study due to their frontline roles requiring strict infection control.

\section{Sample size and sampling technique}

We calculated the sample size of 631 using the Cochran formula for cross-sectional studies based on a prevalence of $70 \%$ of HCWs with good knowledge of IPC from a similar study in Nigeria (12), 4\% precision and $20 \%$ non-response rate. Using a systematic 
sampling technique, we selected the 631 respondents who met our selection criteria from the different groups of HCWs in the hospital, comprising 855 doctors, 1150 nurses, 362 medical laboratory scientists and 300 cleaning staff. The sample size was allocated to each group of HCWs proportionately. The list of workers in each group was drawn, and the sampling interval was estimated for each group and used to systematically sample the required number.

\section{Study instrument and data collection}

A self-administered questionnaire was used to collect information from each respondent. The questionnaire was adapted from previous studies $(9,12)$, and consisted of 4 sections. Section A obtained data on the sociodemographic characteristics of the respondents. Section B obtained data on knowledge of IPC among respondents and questions were on knowledge of most effective method of controlling hospital-acquired infections (HAIs), modes of transmission of HAIs, and the WHO 5 moments of hand hygiene. Section $C$ obtained data on the attitude of respondents towards IPC and the questions were on attitude towards handling of body fluids, hand washing, adherence to IPC policies, IPC training, and recapping of needles. Section D obtained data on practice of IPC among respondents and the questions were on the practice of hand washing and the use of hand gloves.

\section{Data management}

Data were cleaned by checking for consistency and completeness. Analysis was done with EPI INFO version 7.2 and Microsoft Excel 2016. Knowledge of IPC was tested using 12 questions, while 8 and 4 questions were used to assess attitude towards IPC and practice of IPC respectively. Each correct question attracted a score of one and a wrong answer was scored zero. Respondents were classified as having good knowledge if they scored $\geq 75 \%$ of the total scores, fair if scores were $50-74 \%$ and poor if $<50 \%$ (9).

We examined the relationship between good knowledge, attitude and practice of IPC and socio-demographic characteristics using Chi square statistics. The scores were dichotomized (fair and poor were merged together as poor) before the bivariate analysis. All variables with $p$-value less than 0.2 in the bivariate analysis were selected and modeled into the multivariate logistic regression to determine the predictors of good knowledge, attitude and practice of IPC at $5 \%$ level of significance. The crude odds ratio (COR) and adjusted odds ratio (AOR) were reported.

\section{Ethical consideration}

Ethical approval was obtained from the Research and Ethics Committee of Alex Ekwueme Federal University Teaching Hospital. Respondents were informed of their voluntariness to participate in the study, and confidentiality and anonymity of data collected were maintained by avoiding inclusion of possible identifiers, such as names and contact details.

\section{Results:}

Of the $631 \mathrm{HCWs}$ selected for this study, $562 \mathrm{HCWs}$ aged between 22 years and 70 years responded, representing a response rate of $89.1 \%$. The mean age of the respondents was $37.4 \pm 8.1$ years with higher proportion of the respondents $(361,64.2 \%)$ being $<40$ years of age. There were more females $(350,62.3 \%), 327(58.2 \%)$ had $<7$ years work experience, and 447 (79.5\%) had previous training on IPC. Doctors and nurses constituted $67.2 \%$ of the respondents (Table 1).

Among the respondents, 287 (51.1\%) had good knowledge of IPC, $442(78.6 \%)$ had good attitude towards IPC, and 268 (47.7\%) had good practice of IPC. Sociodemographic predictors of IPC knowledge were being a medical laboratory scientist ( $A O R=0.5 ; 95 \%$ $\mathrm{CI}=0.29-0.83 ; p=0.009)$, tertiary education level $(\mathrm{AOR}=7.0 ; 95 \% \mathrm{CI}=1.11-44.60 ; p=$ $0.038)$, and work experience of $\geq 7$ years $(\mathrm{AOR}=2.3 ; 95 \% \mathrm{CI}=1.47-3.57 ; p<0.001)$, while gender, age group, nurse professional, orderly/cleaner, marital status, and previous training in IPC were not significantly associated with knowledge of IPC (Table 2).

In relation to respondents' attitude to IPC, male gender $(A O R=1.9 ; 95 \% C I=1.06-$ $3.42 ; p=0.031$ ), nurse professional (AOR= $6.5 ; 95 \% \mathrm{CI}=2.67-15.81 ; p<0.001)$ and work experience of $\geq 7$ years $(A O R=2.5 ; 95 \%$ $\mathrm{CI}=1.37-4.54 ; p=0.003)$ were predictors of good attitude towards IPC, while age group, medical laboratory scientist, orderly/cleaner, marital status, educational level, and previous training in IPC were not significantly associated with attitude towards IPC (Table 3).

Assessment of respondents' practice of IPC identified nurse professional $(A O R=3.1$; $95 \% \mathrm{CI}=1.79-5.20 ; p<0.001)$ and married status $(\mathrm{AOR}=1.6 ; 95 \% \quad \mathrm{CI}=1.05-2.55 ; \quad p=$ 0.028 ) as predictors of good practice of IPC, while gender, age group, medical laboratory scientist, orderly/cleaner, educational level, work experience, and previous training in IPC were not significantly associated with practice of IPC (Table 4). 
Table 1: Socio-demographic characteristics of selected healthcare workers in Alex Ekwueme Federal University Teaching Hospital, Abakaliki, Nigeria, 2019

\begin{tabular}{|c|c|}
\hline Socio-demographic characteristics & Frequency (\%) \\
\hline \multicolumn{2}{|l|}{ 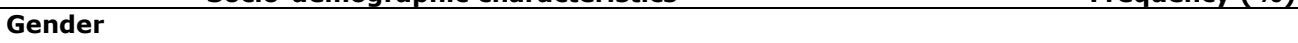 } \\
\hline Female & $350(62.3)$ \\
\hline Male & $212(37.7)$ \\
\hline \multicolumn{2}{|l|}{ Age group } \\
\hline$<40$ years & $361(64.2)$ \\
\hline$\geq 40$ years & $201(35.8)$ \\
\hline \multicolumn{2}{|l|}{ Profession } \\
\hline Doctor & $189(33.6)$ \\
\hline Nurse & $189(33.6)$ \\
\hline Medical Laboratory Scientist & $92(16.4)$ \\
\hline Orderly/Cleaner & $92(16.4)$ \\
\hline \multicolumn{2}{|l|}{ Religion } \\
\hline Christianity & $556(98.9)$ \\
\hline Islam & $4(0.7)$ \\
\hline Traditional Religion & $1(0.2)$ \\
\hline Others & $1(0.2)$ \\
\hline \multicolumn{2}{|l|}{ Marital Status } \\
\hline Single & $126(22.4)$ \\
\hline Married & $423(75.3)$ \\
\hline Separated/Divorced & $13(2.3)$ \\
\hline \multicolumn{2}{|l|}{ Level of Education } \\
\hline No Education & $1(0.2)$ \\
\hline Primary Education & $6(1.1)$ \\
\hline Secondary Education & $80(14.2)$ \\
\hline $\begin{array}{l}\text { Tertiary education } \\
\text { Tut }\end{array}$ & $475(84.5)$ \\
\hline \multicolumn{2}{|l|}{ Work Experience } \\
\hline$<7$ years & $327(58.2)$ \\
\hline$\geq 7$ years & $235(41.8)$ \\
\hline \multicolumn{2}{|l|}{ Previous Training on IPC } \\
\hline Yes & $447(79.5)$ \\
\hline No & $115(20.5$ \\
\hline
\end{tabular}

Table 2: Knowledge of infection prevention and control among selected healthcare workers in Alex Ekwueme Federal University Teaching Hospital, Abakaliki, Nigeria, 2019

\begin{tabular}{|c|c|c|c|c|c|c|}
\hline \multirow[t]{2}{*}{ Variable } & \multicolumn{2}{|c|}{ Knowledge } & \multirow[t]{2}{*}{ COR $(95 \% \mathrm{CI})$} & \multirow[t]{2}{*}{$p$-value } & \multirow[t]{2}{*}{ AOR $(95 \% \mathrm{CI})$} & \multirow[t]{2}{*}{$p$-value } \\
\hline & Good & Poor & & & & \\
\hline \multicolumn{7}{|l|}{ Gender } \\
\hline Female & $185(52.9)$ & $165(47.1)$ & $1.2(0.86-1.70)$ & 0.276 & & \\
\hline Male & $102(48.1)$ & $110(51.9)$ & 1 & & & \\
\hline \multicolumn{7}{|l|}{ Age } \\
\hline$\geq 40$ years & $127(63.2)$ & $74(36.8)$ & $2.2(1.51-3.07)$ & $<0.001$ & $1.3(0.80-1.98)$ & 0.329 \\
\hline$<40$ years & $160(44.3)$ & $201(55.7)$ & 1 & & 1 & \\
\hline \multicolumn{7}{|l|}{ Profession } \\
\hline Nurses & $136(72.0)$ & $53(28.0)$ & $2.0(1.31-3.08)$ & 0.001 & $1.4(0.89-2.25)$ & 0.144 \\
\hline $\begin{array}{l}\text { Medical Laboratory } \\
\text { scientist }\end{array}$ & $40(43.5)$ & $52(56.5)$ & $0.6(0.36-0.99)$ & 0.048 & $0.5(0.29-0.83)$ & $0.009 *$ \\
\hline Orderly/Cleaner & $5(5.4)$ & $87(94.6)$ & $0.1(0.02-0.12)$ & $<0.001$ & $0.2(0.04-1.10)$ & 0.064 \\
\hline Doctors & $106(56.1)$ & $83(43.9)$ & 1 & & 1 & \\
\hline \multicolumn{7}{|l|}{ Marital Status } \\
\hline Married & $234(55.3)$ & $189(44.7)$ & $2.0(1.36-2.97)$ & $<0.001$ & $1.1(0.66-1.71)$ & 0.803 \\
\hline Others & $53(38.1)$ & $86(61.9)$ & 1 & & 1 & \\
\hline \multicolumn{7}{|l|}{ Level of Education } \\
\hline Tertiary Education & $283(59.6)$ & $192(40.4)$ & $30.6(11.03-84.81)$ & $<0.001$ & $7.0(1.11-44.60)$ & $0.038 *$ \\
\hline Others & $4(4.6)$ & $83(95.4)$ & 1 & & 1 & \\
\hline \multicolumn{7}{|l|}{ Work Experience } \\
\hline$\geq 7$ years & $153(65.1)$ & $82(34.9)$ & $2.7(1.90-3.80)$ & $<0.001$ & $2.3(1.47-3.57)$ & $<0.001 *$ \\
\hline$<7$ years & $134(41.0)$ & $193(59.0)$ & 1 & & 1 & \\
\hline \multicolumn{7}{|c|}{$\begin{array}{l}\text { Previous Training on } \\
\text { IPC }\end{array}$} \\
\hline Yes & $226(50.6)$ & $221(49.4)$ & $0.9(0.60-1.37)$ & 0.635 & & \\
\hline No & $61(53.0)$ & $54(47.0)$ & 1 & & & \\
\hline
\end{tabular}


Table 3: Attitude towards infection prevention and control among selected healthcare workers in Alex Ekwueme Federa University Teaching Hospital, Abakaliki, Nigeria, 2019

\begin{tabular}{|c|c|c|c|c|c|c|}
\hline \multirow[t]{2}{*}{ Variable } & \multicolumn{2}{|c|}{ Attitude } & \multirow[t]{2}{*}{ COR (95\% CI) } & \multirow[t]{2}{*}{$p$-value } & \multirow[t]{2}{*}{ AOR (95\% CI) } & \multirow[t]{2}{*}{$p$-value } \\
\hline & Good & Poor & & & & \\
\hline \multicolumn{7}{|l|}{ Gender } \\
\hline Male & $175(82.6)$ & $37(17.4)$ & $1.5(0.96-2.26)$ & 0.079 & $1.9(1.06-3.42)$ & $0.031 *$ \\
\hline Female & $267(76.3)$ & $83(23.7)$ & 1 & & 1 & \\
\hline \multicolumn{7}{|l|}{ Age } \\
\hline$\geq 40$ years & $174(86.6)$ & $27(13.4)$ & $2.2(1.40-3.58)$ & 0.001 & $1.0(0.52-1.77)$ & 0.891 \\
\hline$<40$ years & $268(74.2)$ & $93(25.8)$ & 1 & & 1 & \\
\hline \multicolumn{7}{|l|}{ Profession } \\
\hline Nurses & $181(95.8)$ & $8(4.2)$ & $5.9(2.67-12.97)$ & $<0.001$ & $6.5(2.67-15.81)$ & $<0.001^{*}$ \\
\hline $\begin{array}{l}\text { Medical Laboratory } \\
\text { Scientist }\end{array}$ & $71(77.2)$ & $21(22.8)$ & $0.9(0.48-1.60)$ & 0.674 & $0.9(0.47-1.72)$ & 0.741 \\
\hline Orderly/Cleaner & $40(43.5)$ & $52(56.5)$ & $0.2(0.12-0.34)$ & $<0.001$ & $1.1(0.24-5.06)$ & 0.911 \\
\hline Doctors & $150(79.4)$ & $39(20.6)$ & 1 & & 1 & \\
\hline \multicolumn{7}{|l|}{ Marital Status } \\
\hline Married & $347(82.0)$ & $76(18.0)$ & $2.1(1.37-3.27)$ & 0.001 & $1.2(0.69-1.97)$ & 0.561 \\
\hline Others & $95(68.4)$ & $44(31.6)$ & 1 & & 1 & \\
\hline \multicolumn{7}{|l|}{ Level of Education } \\
\hline Tertiary education & $406(85.5)$ & $69(14.5)$ & $8.3(5.07-13.70)$ & $<0.001$ & $4.4(0.97-19.57)$ & 0.055 \\
\hline Others & $36(41.4)$ & $51(58.6)$ & 1 & & 1 & \\
\hline \multicolumn{7}{|l|}{ Work Experience } \\
\hline$\geq 7$ years & $208(88.5)$ & $27(11.5)$ & $3.1(1.92-4.89)$ & $<0.001$ & $2.5(1.37-4.54)$ & $0.003^{*}$ \\
\hline$<7$ years & $234(71.6)$ & $93(28.4)$ & 1 & & 1 & \\
\hline \multicolumn{7}{|c|}{$\begin{array}{l}\text { Previous Training on } \\
\text { IPC }\end{array}$} \\
\hline Yes & $348(77.9)$ & $99(22.1)$ & $0.8(0.47-1.33)$ & 0.364 & & \\
\hline No & $94(81.7)$ & $21(18.3)$ & 1 & & & \\
\hline
\end{tabular}

\section{Discussion:}

This study was an assessment of the state of IPC, one year after an outbreak of nosocomial Lassa fever among HCWs in the study location. Routine assessment of health systems is key to improving healthcare services delivery through identifying strengths and weaknesses and working towards fixing identified weaknesses. In our study location, there was an initial assessment of IPC which identified gaps during the nosocomial outbreak in $2018(8,9)$. Several interventions had been carried out in the hospital to improve IPC after the initial assessment, and the hospital management in conjunction with her partners had organized series of training on IPC among its health workforce. The partners had supported the hospital in improving its IPC infrastructures.

Despite the series of training that had been conducted in the preceding year prior to this study, only about half $(51.1 \%)$ of the respondents had good knowledge of IPC. Findings from the initial assessment in 2018 (9) had recorded a higher proportion $(71.9 \%)$ of hospital staff with good knowledge of IPC (9) however, the sample size used in this initial assessment was small $(n=135)$ and the professional distribution of the study participants might have been different. Some other findings from Nigeria and Ethiopia reported higher proportions with good IPC knowledge (12-14). But these studies used a smaller sample size and a lower cut-off to adjudge good knowledge of IPC. A study in Ethiopia with similar sample size $(n=649)$ had a similar proportion $(53.7 \%)$ of HCWs with good knowledge of IPC; hence small sample size might be the major factor for the difference in good knowledge of IPC observed in other studies. The finding showed that there are still gaps in the knowledge of IPC among HCWs. This has implication on practice and risk of healthcare associated infections. It also calls for the need to institutionalize the IPC interventions instead of one-off training interventions. Reinforcing the training and practice of IPC will likely have synergistic effect on knowledge and practice of IPC in healthcare settings.

There were several predictors of good knowledge of IPC. Although doctors were twice more likely to have good knowledge of IPC compared to medical laboratory scientists, 
Table 4: Practice of infection prevention and control among selected healthcare workers in Alex Ekwueme Federal University Teaching Hospital, Abakaliki, Nigeria, 2019

\begin{tabular}{|c|c|c|c|c|c|c|}
\hline \multirow[t]{2}{*}{ Variable } & \multicolumn{2}{|c|}{ Practice } & \multirow[t]{2}{*}{ COR (95\% CI) } & \multirow[t]{2}{*}{ p-value } & \multirow[t]{2}{*}{ AOR (95\% CI) } & \multirow[t]{2}{*}{$p$-value } \\
\hline & Good & Poor & & & & \\
\hline \multicolumn{7}{|l|}{ Gender } \\
\hline Female & $180(51.4)$ & $170(48.6)$ & $1.5(1.06-2.11)$ & 0.023 & $0.9(0.58-1.45)$ & 0.718 \\
\hline Male & $88(41.5)$ & $124(58.5)$ & 1 & & 1 & \\
\hline \multicolumn{7}{|l|}{ Age group } \\
\hline$\geq 40$ years & $110(54.7)$ & $91(45.3)$ & $1.6(1.10-2.20)$ & 0.013 & $1.0(0.62-1.45)$ & 0.808 \\
\hline$<40$ years & $158(43.8)$ & $203(56.2)$ & 1 & & 1 & \\
\hline \multicolumn{7}{|l|}{ Profession } \\
\hline Nurses & $126(66.7)$ & $63(33.3)$ & $3.3(2.18-5.07)$ & $<0.001$ & $3.1(1.79-5.20)$ & $<0.001 *$ \\
\hline $\begin{array}{l}\text { Medical Laboratory } \\
\text { Scientist }\end{array}$ & $39(42.4)$ & $53(57.6)$ & $1.2(0.74-2.03)$ & 0.437 & $1.3(0.73-2.14)$ & 0.424 \\
\hline Orderly/Cleaner & $32(34.8)$ & $60(65.2)$ & $0.9(0.53-1.49)$ & 0.650 & $1.0(0.25-4.36)$ & 0.963 \\
\hline Doctors & $71(37.6)$ & $118(62.4)$ & 1 & & 1 & \\
\hline \multicolumn{7}{|l|}{ Marital Status } \\
\hline Married & $222(52.5)$ & $201(47.5))$ & $2.2(1.50-3.34)$ & $<0.001$ & $1.6(1.05-2.55)$ & $0.028^{*}$ \\
\hline Others & $46(33.1)$ & $93(66.9)$ & 1 & & 1 & \\
\hline \multicolumn{7}{|l|}{ Level of Education } \\
\hline Tertiary Education & $238(50.1)$ & $237(49.9)$ & $1.9(1.18-3.08)$ & 0.007 & $1.1(0.26-4.56)$ & 0.903 \\
\hline Others & $30(34.5)$ & $57(65.5)$ & 1 & & 1 & \\
\hline \multicolumn{7}{|l|}{ Work Experience } \\
\hline$\geq 7$ years & $130(55.3)$ & $105(44.7)$ & $1.7(1.21-2.38)$ & 0.002 & $1.2(0.78-1.78)$ & 0.438 \\
\hline$<7$ years & $138(42.2)$ & $189(57.8)$ & 1 & & 1 & \\
\hline \multicolumn{7}{|c|}{$\begin{array}{l}\text { Previous Training on } \\
\text { IPC }\end{array}$} \\
\hline Yes & $215(48.1)$ & $232(51.9)$ & $1.1(0.72-1.64)$ & 0.700 & & \\
\hline No & $53(46.1)$ & $62(53.9)$ & 1 & & & \\
\hline
\end{tabular}

*Statistically significant; COR=Crude Odds Ratio; AOR = Adjusted Odds Ratio; Confidence Interval

this was still far below the proportion of nurses with good knowledge of IPC, while the proportion of orderlies/cleaners with good knowledge of IPC was abysmally too low. Those with tertiary education were seven times more likely to have good knowledge compared with others, and those with 7 or more years of work experience were twice more likely to have good knowledge compared to those with less than 7 years of work experience. Some other factors that have been associated with knowledge of IPC included age, gender, work experience, educational status (14), profession (15), and types of facility $(16,17)$, were also reported in this study.

About three-quarter $(78.6 \%)$ of the respondents had good attitude towards IPC. This may be due to the nosocomial Lassa fever infection that had affected their colleagues severally and sometimes resulting in deaths. However, a similar study reported a higher percentage $(93.4 \%)$ of HCWs with good attitude towards IPC (18) while another study reported a lower percentage $(55.6 \%)$ of HCWs who had positive attitude about infection prevention (17). The difference noticed in these studies may be due to variation in study setting and the composition of study respondents. A good attitude towards IPC is desired because this is expected to result in good practice which is protective for the HCWs. We also found that males were about twice more likely to have good attitude towards IPC compared to the females while nurses were about 7 times more likely to have good attitude compared to doctors. However, the finding of males being more likely to have good attitude of IPC may have been influenced by confounders. Females have been reported to have better IPC attitude as some IPC practices may be associated with householdtype chores, which may be seen as women's work and therefore feminine (19). This may also be the reason for nurses being more likely to have good attitude compared to doctors as nursing is dominated by females why medical practice in Nigeria is dominated by males. Also, those with 7 or more years of work experience were about three times more likely to have good attitude compared to those with lesser years of work experience. It is possible 
that with increasing years of work experience, HCWs may tend to have a better attitude towards IPC due to increasing understanding of the risks associated with healthcare.

In this study, less than half $(47.7 \%)$ of the respondents had good practice of IPC. A recent study in Nigeria reported $68 \%$ of HCWs with good practice of IPC (16). As observed in our study, it was noticed that good practice of IPC was lower than knowledge and attitude about IPC as reported in some other studies $(12,16-18)$. This might suggest that knowledge of IPC does not translate to good practice. Some researchers have reported weak correlation between good knowledge and good practice of IPC $(12,20)$. This may be connected to the fact that other factors such as availability of the IPC infrastructure, personal protective equipment (PPE) and presence or otherwise of organizational cultures and policy determine how individuals practice IPC in different settings. Our hospital has an IPC committee, and has developed IPC policy but this has not been distributed in the hospital while supply of PPE are still not optimum. These could also be contributory and need to be addressed.

Other factors have also been reported to be associated with good practice of IPC. In our study, nurses were three times more likely to have good practice of IPC compared to doctors. Also, the married HCWs were 1.6 times more likely to practice IPC compared to the unmarried. In some studies, age, educational status, and years of work experience $(14,15,17)$, profession $(15)$, level of healthcare facility (17), continuous supply of PPE (17), presence of IPC guidelines (15), working in department with continuous water supply (21), gender and type of department (18), have been reported to be associated with good practice of IPC.

\section{Conclusion:}

The study shows that knowledge and practice of IPC are still low in the study location despite the interventions that had been instituted to improve the IPC framework. Therefore, there is need to adapt approaches that will influence behavior change towards IPC in the course of the series of in-service training being conducted in the hospital. Also, there is need to set up an IPC surveillance structure in the study location so as to support $\mathrm{HCW}$ in the course of their routine work in the hospital.

\section{Conflict of interest:}

Authors declare no conflict of interest

\section{Source of funding:}

No grant was received for this study

\section{References:}

1. Asogun, D. A., Günther, S., Akpede, G. O., Ihekweazu, C., and Zumla, A. Lassa Fever: Epidemiology, Clinical Features, Diagnosis, Management and Prevention. Infect Dis Clin North Am. 2019; 33 (4): 933-951.

2. Nigeria Centre for Disease Control. Lassa fever. 2019. https://www.ncdc.gov.ng/diseases/info/L. Accessed April 42020.

3. Nigeria Centre for Disease Control. Lassa fever Healthcare Worker Advisory. 2020

https://ncdc.gov.ng/news/212/lassa-fever-

4. Akpede, G. O., Asogun, D. A., Okogbenin, S. A., et al. Caseload and Case Fatality of Lassa fever in Nigeria, 2001-2018: A Specialist Center's Experience and its Implications. Front Publ HIth. 2019; 7 (170): 2001-2018.

5. Yassi, A., Zungu, M., Spiegel, J. M., et al. Protecting health workers from infectious disease transmission: an exploration of a Canadian-South African partnership of partnerships. Global Health. 2016; 12 (1): 1-15.

6. Ehichioya, D. U., Hass, M., Ölschläger, S., et al. Lassa fever, Nigeria, 2005-2008. Emerg Infect Dis. 2010; 16 (6): 1040-1041.

7. Ajayi, N. A., Nwigwe, C. G., Azuogu, B. N., et al. Containing a Lassa fever epidemic in a resourcelimited setting: Outbreak description and lessons learned from Abakaliki, Nigeria (January-March 2012). Int J Infect Dis. 2013; 17 (11): 1011-1016.

8. Dan-Nwafor, C. C., Ipadeola, O., Smout, E., et al. A cluster of nosocomial Lassa fever cases in a tertiary health facility in Nigeria: description and lessons learned, 2018. Int J Infect Dis. 2019; 83: 88-94.

9. Odegbemi, O. B., Umeokonkwo, C. D., Nwachukwu, W., et al. Infection prevention and control in a treatment centre during a Lassa fever outbreak in southeastern Nigeria - January, 2018. Glob Biosecurity. 2019; 1 (3):

https://jglobalbiosecurity.com/article/10.31646/g bio.44/.

10. World Health Organization. Infection Prevention and Control. https://www.who.int/infectionprevention/about/ipc/en/. Accessed June 222020.

11. Umeokonkwo, C. D., Madubueze, U.C., Onah, C. $\mathrm{K}$. , et al. Point prevalence survey of antimicrobial prescription in a tertiary hospital in South East Nigeria: A call for improved antibiotic stewardship. ] Glob Antimicrob Resist. 2019; 17. 291-295.

12. Iliyasu, G., Dayyab, F. M., Habib, Z. G., et al. Knowledge and practices of infection control among healthcare workers in a Tertiary Referral Center in North-Western Nigeria. Ann Afr Med. 2016; 15 (1): 34-40.

13. Famakinwa, T., Bello, B., Oyeniran, Y., Okhiah, O., and Nwadike, R. Knowledge and Practice of PostOperative Wound Infection Prevention among Nurses in the Surgical Unit of a Teaching Hospital in Nigeria. Int J Basic, Appl Innov Res. 2014; 3 (1): 23-28.

14. Desta, M., Ayenew, T., Sitotaw, N., Tegegne, N., Dires, M., and Getie, M. Knowledge, practice and associated factors of infection prevention among healthcare workers in Debre Markos referral hospital, Northwest Ethiopia. BMC Health Serv Res. $2018 ; 18$ (465):

https://doi.org/10.1186/s12913-018-3277-5

15. Geberemariyam, B. S., Donka, G. M., and Wordofa B. Assessment of knowledge and practice of health 
workers towards infection prevention and associated factors in healthcare facilities of West Arsi District, Southeast Ethiopia : a facility-based cross-sectional study. Arch Public Health. 2018;76 (69):

https://doi.org/10.1186/s13690-018-0314-0.

16. Adebimpe, W. O., Folayan, W., Shittu, A. A. Adebimpe, M. A., and Ibirongbe, D. Infection Prevention and Control Practices among Health-Care Workers in Tuberculosis Clinics in Ondo State, Nigeria. Libyan J Med Sci. 2019; 3 (2): 51-65

17. Gulilat, K. Assessment of Knowledge, Attitude And Practice of Health Care Workers on Infection Prevention in Health Institution Bahir Dar City Administration. Sci J Publ HIth. 2014; 2 (5): 384393.

18. Hussen, S., Estifanos, W., Melese, E., and Moga F. Knowledge, Attitude and Practice of Infection
Prevention Measures among Health Care Workers in Wolaitta Sodo Otona Teaching and Referral Hospital. J Nurs Care. 2017; 6 (4):

doi:10.4172/2167-1168.1000416

19. Ward, D. Gender differences in compliance with infection control precautions. Br J Infect Control. 2004; 5 (1): 17-19.

20. Ogoina, D., Pondei, K., Adetunji, B., Chima, G. Isichei, C., and Gidado, S. Knowledge, attitude and practice of standard precautions of infection control by hospital workers in two tertiary hospitals in Nigeria. J Infect Prev. 2015; 16 (1): 16-22.

21. Biniyam, S., Sahiledengle, B., Gebresilassie, A., Getahun, T., and Hiko, D. Infection Prevention Practices and Associated Factors among Healthcare Workers in Governmental Healthcare Facilities in Addis Ababa. Ethiop J Hlth Sci. 2018; 28 (2): 177-186. 